\title{
10. Labour market issues
}

\section{Matthew Gray and Bruce Chapman}

The continuing low employment rates and general labour market disadvantage of Indigenous Australians have been well documented (Altman \& Nieuwenhuysen 1979; Daly 1995; Hunter 2004a). However, our understanding of the reasons for this labour market disadvantage is constrained by the limited data available for the Indigenous population. This lack of understanding hampers the development of labour market and related policies to improve labour market outcomes for Indigenous Australians.

Before the collection of the 2002 NATSISS, the main source of data on Indigenous labour force status - and the only sources of data that could be used to reliably measure change - have been the five-yearly censuses from 1971 to 2001 . $^{1}$ While the census data can provide valuable information on trends in labour force status, working hours, occupation and industry, there is very limited information on other important labour market topics such as the duration of unemployment, difficulties experienced in finding employment, and the identification of discouraged workers. Furthermore, the census has very limited or no data on a range of economic, demographic, social and cultural factors which are likely to be important in explaining labour market outcomes.

The only other nationally representative data on Indigenous Australians is the 1994 NATSIS. ${ }^{2}$ Although the 1994 NATSIS provides data on a much wider range of topics than the census, these data are now over a decade old, and the 2002 NATSISS provides a valuable new source of information on labour market issues.

The 2002 NATSISS collects similar information to the 1994 NATSIS on labour market issues, so it represents a valuable and timely addition to data sets with information on Indigenous labour market outcomes. In broad terms, the information on key labour market variables is comparable between the 1994 NATSIS and 2002 NATSISS, allowing for changes over time to be assessed. ${ }^{3}$

\footnotetext{
${ }^{1}$ However, it should be noted that the ABS has recently released some experimental estimates from the LFS (ABS 2006).

2 There are a number of data sets which contain limited information on labour market issues and which have a sufficient Indigenous sample to allow meaningful analysis. Examples are the 1995 and 2002 National Health Surveys collected by the ABS. There are also surveys of specific groups of Indigenous people, such as the longitudinal survey of Aboriginal and Torres Strait Islander job-seekers collected by the then Department of Employment, Workplace Relations and Small Business.

3 There are issues relating to the sampling which need to be taken into account when making comparisons between these two surveys. They are discussed in detail by Biddle \& Hunter in this volume.
} 
The purpose of this chapter is to provide an overview of the labour market information available in the 2002 NATSISS and to describe some of the key strengths and limitations of the data. In order to illustrate the value of the 2002 NATSISS, three examples are offered of highly useful types of data that are available.

While no data set is ideal, we consider in some detail an important limitation of the 2002 NATSISS data. This relates to the omission of key variables from the data set, specifically labour market experience and the length of time spent with the current employer. We use an alternative data set with information on labour market experience to illustrate the potential significance of its omission for statistical analysis of both wages and joblessness. The value of our method is that it can be applied to illustrate the significance or otherwise of the omission of other variables from the 2002 NATSISS.

Other chapters in this volume (Biddle \& Hunter; Webster, Rogers \& Black) and a number of ABS publications provide a detailed overview of the 2002 NATSISS, including sampling, exclusions issues and non-sampling matters. In this chapter, discussion of these issues is limited to those that are specifically related to the labour market data in NATSISS.

\section{Strengths of the 2002 NATSISS}

There are three main areas in which the 2002 NATSISS data has advantages over the census for the analysis of labour market issues.

First, the 2002 NATSISS accurately identifies CDEP scheme employment, which is not the case in the census. ${ }^{4}$ This is a major limitation of the census because the CDEP scheme represents a crucial difference between Indigenous and mainstream labour market experiences. Under the scheme, funding is allocated to CDEP organisations for remuneration for participants at a level similar to, or a little higher than, income support payments, with the finances being enhanced with administrative and capital support. It is thus used as a means to provide employment, training and enterprise support to Indigenous participants (see Altman, Gray \& Levitus 2005 for a detailed discussion of the CDEP scheme). To illustrate how important the scheme is, we note that in 2002, employment in CDEP accounted for over one-quarter of the total employment of Indigenous Australians, with around 13 per cent of the Indigenous working-age population being employed in the scheme.

4 CDEP employment is not reliably identified by the census because the census form does not include CDEP employment as a separate category, although in the 1996 and 2001 censuses a different census form (the Special Indigenous Form, or SIF) was used in some discrete Indigenous communities. The SIF has a separate category for CDEP employment. Although this has improved identification of CDEP employment, many Indigenous people participating in the CDEP scheme are not enumerated using the SIF. Administrative data on CDEP participants for the time of the 2001 Census indicates that 30474 Indigenous people worked in the scheme, whereas the census identifies only 17800 participants (Hunter 2004a: 5). 
The importance of identifying CDEP employment for different areas of Australia is illustrated in Table 10.1, which shows Indigenous labour force status by region using the 2002 NATSISS. ${ }^{5}$ In non-remote areas, just 4.7 per cent of the Indigenous working-age population was employed in the CDEP scheme. In these areas, failure to take account of CDEP employment is likely to have a relatively small effect. But in remote and very remote areas, 16.9 per cent and 42.2 per cent respectively of the working age population was employed in the scheme (see Table 10.2).

Table 10.1. Indigenous labour force status by region, 2002

\begin{tabular}{lrrr}
\hline & Non-remote & Remote & Very remote \\
& $\%$ & $\%$ & $\%$ \\
\hline Employed & & & 42.2 \\
CDEP employed & 4.7 & 16.9 & 14.9 \\
Mainstream employed & 41.2 & 31.7 & 61.6 \\
Total in the labour force & 63.3 & 58.7 & 49850 \\
Population (no.) & 196300 & 23100 & a \\
\hline
\end{tabular}

a. Table population is Indigenous persons aged 15-64 years.

Note: The remote areas in this chapter, in contrast to most other chapters in this monograph, refers to remote areas that are not classified as very remote by ARIA. That is, tables are not derived from ABS (2004c), which generally provides aggregate results for all remote areas.

Source: Customised cross-tabulations from the 2002 NATSISS (derived from Altman, Gray \& Levitus 2005: Table 1)

Using the 2002 NATSISS, it is possible to estimate the effects of CDEP employment on a range of important outcomes, such as income and working hours. With the 1994 NATSIS, it also allows for analysis of trends in labour force status (including non-CDEP employment) to be identified with more confidence than has been previously possible using census data combined with administrative data. It is also possible to analyse changes in the determinants of mainstream employment at an individual level (although not for the same individual, which would require longitudinal data).

Further, the 2002 NATSISS can also be used to estimate the associations between CDEP employment and a range of social, health and cultural variables.

The second major advantage of the 2002 NATSISS is that, for the first time, analysis of labour market issues is possible in very remote areas of Australia. The ability to do this is highly valuable because the labour market context of very remote areas (and, to a lesser extent, remote areas) is very different from those in the rest of Australia, for reasons now discussed.

First, Indigenous people in very remote areas are often living in communities in which the majority of the population is Indigenous. Second, these communities are in sparsely populated regions of Australia which are extremely distant from

${ }^{5}$ It is possible to analyse labour force status for the following geographic categories: non-remote, remote and very remote. In Table 10.1, we have aggregated areas into the categories of 'non-remote', 'remote' and 'very remote' in order to simplify the analysis and allow us to highlight the major issues. 
markets, both geographically and culturally. Third, these regions were colonised relatively late, with some parts of Arnhem Land and central Australia as recently as during the last 50 years. This has meant that customary (kin-based) systems and practices remain robust and there is ongoing contestation between mainstream Australian and Indigenous world views.

Furthermore, according to conventional economic and social indicators, there is a growing disparity between Indigenous people living in remote areas and both Indigenous and non-Indigenous Australians living in non-remote areas (ABS 2004a, 2004c). There is evidence that some discrete Indigenous communities in remote Australia are in economic and social crisis.

The different labour market context in respective regions is illustrated clearly by the fact that in non-remote areas the mainstream employment rate is 41.2 per cent, in remote areas 31.7 per cent, and in very remote areas just 14.9 per cent (see Table 10.1). Human capital and demographic characteristics also differ dramatically across regions. For example, education levels are much lower in remote and very remote areas than in non-remote areas, and the proportion of the population speaking an Indigenous language is much higher in remote areas than in non-remote areas. These factors are bound to influence the nature, variance and quality of Indigenous labour market experiences and it is a real bonus that the information is part of the 2002 NATSISS.

A third advantage of the 2002 NATSISS is that it contains information on a wide range of somewhat unusual social, demographic, cultural, and economic variables which are potentially important for understanding labour market outcomes. Examples include health status, speaking an Aboriginal language, having used an employment service, access to transport, and having been arrested. Note that many of these variables are not available from the census. 
Table 10.2. Labour market data collected in the 2002 NATSISS

\begin{tabular}{ll}
\hline Labour force status & Employment support \\
Duration of unemployment & Whether used employment support services \\
Hours usually worked in all jobs & Whether needed employment support services \\
Full-time/part-time status & Reasons did not use employment support services \\
Employment sector & Income \\
Precariousness - job security in next 12 months & Level of income \\
Whether work allows for cultural responsibilities & Personal gross weekly income \\
& Household gross weekly income \\
CDEP: & Source of income \\
Whether CDEP participant & All sources of personal income \\
Duration on CDEP & Main source of personal income \\
Considers CDEP participation to be a job & Government pension/allowance \\
Barriers to employment & Type of government pension/allowance (primary) \\
Whether had difficulties finding work & Type of government pension/allowance (auxiliary) \\
All difficulties finding work & Government support \\
Main difficulty finding work & Time on government support in last two years \\
Discouraged jobseekers & \\
Whether would like a job & \\
All reasons not looking for a job & \\
\hline
\end{tabular}

Source: Derived from ABS (2005b)

In general, it appears that questions relating to labour market topics are very similar (virtually identical) in the community and non-community questionnaires (see ABS 2005b and the list of variables in Table 10.2). While there may be some effects generated by differences in the data collection method (CAPI versus paper-based questionnaire), we do not anticipate this will have introduced major biases. While those analysing the data will need to carefully consider the extent to which the remote and non-remote data is comparable for their particular application, our reading of the questionnaires suggests that there is no particular reason for expecting there to be comparability issues.

The questions are also, in large part, standard ABS questions. This allows comparative studies of labour market outcomes for Indigenous and non-Indigenous Australians using the 2002 NATSISS and other data sets, such as the GSS.

\section{An illustration of new information available from the 2002 NATSISS}

The 2002 NATSISS, for the first time, provides information on how long CDEP participants have been participating in the CDEP scheme. Information of this type is important in assessing whether CDEP employment is a destination or a stepping stone to mainstream employment. While there are some ambiguities in the NATSISS question, 'How long have you been on $\mathrm{CDEP}^{\prime}$, it does provide valuable data. One difficulty with the question is that it is unclear whether participants who had multiple spells of CDEP would give the duration of CDEP 
participation as from when they first participated in the scheme or whether it would be from when they most recently started on the scheme.

The length of time that participants spend on the CDEP scheme varies across regions. In very remote areas, 40.6 per cent of participants had been on the CDEP scheme for five years or more and 21.8 per cent had been on the CDEP scheme for less than one year (see Table 10.3). Similarly, in remote areas, many participants had been on the scheme for a number of years, although the average duration was shorter. In non-remote areas, only a minority of participants $(15.2 \%)$ had been on the scheme for five years or more and 38.0 per cent had been on the scheme for less than one year.

When interpreting these figures it should be kept in mind that the length of time that a person can be on the CDEP scheme is constrained by the length of time a CDEP scheme place has been available to them. On average, places have been available for longer in remote and very remote areas. It will also depend on the age of the participant, although this could be taken into account in a more sophisticated analysis of the data.

Table 10.3. Duration on CDEP by region of residence, $2002^{\mathrm{a}}$

\begin{tabular}{lrrr}
\hline Length of time on scheme & Non-remote & Remote & Very remote \\
& $\%$ & $\%$ & 21.8 \\
\hline Less than 1 year & 38 & 29.7 & 14.7 \\
1 to less than 2 years & 17.4 & 10.8 & 12.2 \\
2 to less than 3 years & 14.1 & 13.5 & 7.1 \\
3 to less than 4 years & 8.7 & 10.8 & 3.6 \\
4 to less than 5 years & 6.5 & 10.8 & 40.6 \\
5 years or more & 15.2 & 24.3 & 21100 \\
Population (no.) & 9200 & 3900 & \\
\hline
\end{tabular}

a. Table population is CDEP participants.

Source: The 2002 NATSISS, derived from Altman, Gray and Levitus (2005: Table 5)

Another important topic on which the 2002 NATSISS provides new information is participation in vocational education and training (VET). Participation in VET is an important way in which those with low education can increase their skill level and improve their labour market outcomes. Of particular interest is the extent to which CDEP scheme participants receive VET, and hence are improving skill levels and chances of finding mainstream employment. This is an important policy objective of the scheme.

Table 10.4 presents information on participation in the VET sector by labour force status and region in the previous 12 months. There are relatively high rates of participation in VET in the last 12 months in all areas, although rates in very remote areas are half those in major cities. The CDEP employed overall have lower rates of undertaking VET than the mainstream employed. The only exception is in major cities where 54.8 per cent of the CDEP employed undertook VET, compared to 46.9 per cent of the mainstream employed. 
Table 10.4. Participation in VET in the last 12 months, by labour force status and region, $2002^{\mathrm{a}}$

\begin{tabular}{lrrrrr}
\hline & Major cities & Inner regional & Outer regional & Remote & Very remote \\
& $\%$ & $\%$ & $\%$ & $\%$ & $\%$ \\
\hline CDEP & 54.8 & 45.8 & 45.9 & 30.8 & 18.0 \\
Mainstream & 46.9 & 51.7 & 52.8 & 57.5 & 43.2 \\
Unemployed & 27.5 & 21.2 & 25.5 & 26.1 & 13.6 \\
NILF & 2.8 & 2.1 & 7.1 & 3.7 & 1.6 \\
Total & 31.0 & 28.5 & 30.5 & 29.0 & 15.9 \\
\hline
\end{tabular}

a. Table population is Indigenous persons aged 15-64 years.

Source: The 2002 NATSISS, derived from Altman, Gray and Levitus (2005: Table 10)

\section{A limitation of the survey}

All surveys have both strengths and weaknesses, and the above discussion has highlighted aspects of the former with respect to the 2002 NATSISS. What now follows considers some deficiencies of these data, in particular the lack of useful information concerning labour market experience. Specifically, the data set has no measures of either the length of time individuals have spent in paid employment (general labour market experience) or how long employed individuals have been in their current place of work (tenure). The discussion now examines the potential significance of the omission from the data of measures of general labour market experience).

An important focus of modern labour economics concerns the role of skills or, to use the accepted parlance, human capital. Human capital is seen to be a major - even the major - contributor to individuals' success or otherwise in the labour market. There are two important aspects of human capital: formal education and the skills acquired by individuals from on-the-job training. In both areas, there are significant issues associated with measurement, since the pure human capital aspects of both education and training are not directly observed.

Labour market experience is typically represented in surveys like the 2002 NATSISS by the length of time spent in paid employment. Unfortunately, this variable is unavailable in the survey, and this raises the possibility that labour market statistical analyses of the 2002 NATSISS will provide inadequate, even misleading, results concerning the true determinants of Indigenous labour market success or failure.

Not having information on labour market employment history can be seen to be a major weakness of the 2002 NATSISS. In part, this is because Indigenous Australians have much higher rates of movement between labour force states than non-Indigenous Australians (Gray \& Hunter 2005) and have much more interrupted labour market histories. For example, using a longitudinal sample of Indigenous job-seekers, Hunter, Gray \& Jones (2000) find that 33.6 per cent 
of Indigenous males and 37.6 per cent of Indigenous females had been employed for less than 25 per cent of the time since leaving school. Only 16.5 per cent and 18.0 per cent of Indigenous males and females respectively had been employed for more than 75 per cent of the time since leaving school.

In order to illustrate the extent of the potential problem associated with the omission of measures of labour market experience from the 2002 NATSISS, we have examined econometric modelling in two areas: wages and being in employment. Our aim is to demonstrate the likely empirical importance of having to use the wrong variable. Our approach is to use an alternative data set that contains both a poor and a better measure of labour market experience. The poor measure is the length of time individuals could have spent in the labour force after finishing formal education, and the better measure is the number of years an individual has actually spent in paid employment. The models are estimated using both labour market experience measures and the results compared. One such data set can be derived from the HILDA survey.

We have chosen the female sample, since the potential significance of not having the more correct experience measure will be greater for groups with less attachment to the paid labour force, such as women (and Indigenous individuals). The econometric models are now briefly described.

Wage determination exercises take many forms, with the most basic human capital approach being represented by the following equation:

$$
\text { Wage }=\mathrm{a}+\mathrm{b}^{*} \mathrm{EXP}+\mathrm{c}^{*} \mathrm{EXP} 2+\mathrm{d}^{*} \mathrm{YOS}+\mathrm{e}
$$

Where wage is the log of the hourly wage received by the individual, EXP is the number of years of paid employment, and YOS is the number of years of formal education. EXP2 is the square of the experience term, which is included because it is believed that the wage-experience term is non-linear. Table 10.5 compares the coefficients from the estimation of this wage equation (with the $\log$ of wages as the dependent variable) for the 2002 NATSISS specification and the HILDA specification.

Table 10.5. OLS wage regressions ${ }^{a}$

\begin{tabular}{lrr}
\hline Explanatory variables & 2002 NATSISS & HILDA \\
\hline EXP & .0203 & .0287 \\
EXP2 & -.000383 & -.000758 \\
YOS & .0572 & .0525 \\
Constant & 1.618 & 1.689 \\
$\mathrm{R}^{-2}$ & & \\
\hline
\end{tabular}

a. All coefficients are significant at the $1 \%$ level.

Source: Author's calculations

While the results are apparently similar for the two specifications (certainly the coefficients on years of schooling are very close), closer inspection suggests that 
at low levels of measured experience there are significant differences in the wage relationships. This is illustrated in Table 10.6, which shows the percentage change in individuals' hourly wages for additional years of experience at different levels of experience.

Table 10.6. Effect of experience on wage (percentage)

\begin{tabular}{lrrr}
\hline Experience (in years) & NATSIS & HILDA & Percentage difference \\
\hline 1 & 1.95 & 2.72 & 40 \\
5 & 1.65 & 2.11 & 28 \\
10 & 1.25 & 1.35 & 7 \\
\hline
\end{tabular}

Source: Author's calculations

The results of Table 10.6 suggest the following:

- At one year of experience, the effect of an additional year of experience on wages is estimated to be 1.95 per cent using the (poor) measure of experience available from the 2002 NATSISS, compared to about 2.9 per cent using the (better) measure of experience available from HILDA. This difference can be argued to be the very large difference of around 40 per cent of the NATSISS coefficient.

- At moderate levels of experience (e.g., five years), HILDA still results in a higher wage-experience relationship than that found for the 2002 NATSISS, but the difference has been reduced to about 28 per cent.

- At high levels of experience (10 years), there is effectively no difference found between the wage-experience estimates.

We then repeated the above exercise with respect to estimating the determinants of whether or not a person is employed. The typical econometric approach used in this area takes an equation of the following form:

$$
\mathrm{EP}=\mathrm{a}+\mathrm{bEXP}+\mathrm{cEXP} 2+\mathrm{dEDUC}+\mathrm{eDEMOGRAPHY}+\mathrm{e}
$$

Where EP is the probability that an individual is employed, EDUC are measures of education and DEMOGRAPHY reflects demographic factors. In our exercise, DEMOGRAPHY includes measures of marital status, whether or not the person is an immigrant, and the presence and age of children. The major relationship sizes for both specifications are available from the authors, and the experience effects are now shown in Table 10.7.

Table 10.7. Effect of experience on probability of employment (percentage)

\begin{tabular}{lrrr}
\hline Experience (in years) & NATSIS & HILDA & Percentage difference \\
\hline 1 & 2.08 & 4.70 & 226 \\
10 & 1.03 & 2.70 & 262 \\
25 & 0.80 & 0.60 & 75 \\
\hline
\end{tabular}

Source: Author's calculations

The data of Table 10.7 suggest strongly that the poor measure of labour market experience available from the 2002 NATSISS has a significant potential to be 
misleading with respect to the effects of labour market experience on employment. The following results can be highlighted:

- At one year of experience, the 2002 NATSISS estimation suggests an additional year of measured experience increases the probability of employment by about two percentage points, but the (more accurate) experience measure from HILDA suggests that the relationship is more than double this, at nearly five percentage points.

- At 10 years of experience, the estimated differences between the two data sets in the role played by labour market experience is even higher: about one per cent for NATSSISS 2002, and nearly three percentage points for HILDA, a difference of over 250 per cent.

- At very high levels of labour market experience, 25 years, the apparent problem with using the NATSSIS 2002 experience measure has been reduced considerably, to the extent that the poor experience measure now apparently overstates the effect of experience on employment probabilities ( 0.8 compared to 0.6 from HILDA).

These comparative exercises make it apparent that the statistical problem associated with the omission in the 2002 NATSISS of a good measure of labour market experience are potentially very important. By comparing the same modelling with results found with a data set which has available a better measure of experience, it is clear that the 2002 NATSISS understates the value of experience for wages, and that this understatement becomes less as the experience measure increases. Similarly, results on the determinants of employment using the 2002 NATSISS seem to importantly get the story wrong with respect to the true role of experience. And, as with wages, the extent of the problem seems to be greater at the lower levels of experience.

It is important to record that the interpretation difficulties associated with the 2002 NATSISS not having an accurate measure for labour market experience seem to be confined to estimation of the true role of experience. In other words, the modelling and data problem has not affected estimates of the role of variables such as education with respect to wages, and education and demography with respect to the determinants of employment. This suggests that even though researchers are unlikely to be able to show with accuracy the effect of experience on labour market success, there are no associated difficulties for determining the true role for Indigenous labour market performance of other critical variables.

\section{Concluding comments}

The 2002 NATSISS provides a valuable new source of data on labour market issues for Indigenous Australians. It provides some data on labour market issues that has not previously been available. It also repeats much of the labour market content of the 1994 NATSIS and may allow the estimates made using the 1994 
NATSIS to be updated, and the robustness of findings from the earlier survey tested.

This is a very valuable data source, although there is no direct information on critical variables such as labour market experience and tenure in the current job. These are important variables for understanding many labour market relationships, and their absence will likely restrict the value of some types of analysis.

While the 2002 NATSISS survey will certainly advance our understanding of labour market outcomes, the cross-sectional nature of the survey will make the identification of some causal relationships quite difficult and, in some cases, impossible. A longitudinal labour market study for the Indigenous population needs to be considered seriously. 